\title{
Analysis on the Influence of Stage Development Features about Architectural Color under the Regional Culture Background in Changchun City
}

\author{
$\mathrm{Li}$, Mei ${ }^{1, a}$, Liu, Lu ${ }^{2, b}$ and Zhao, Yilong ${ }^{3, c}$ \\ ${ }^{1}$ School of Architecture and Design, 3066 Tongzhi Street, Changchun, Jilin Province, P.R.China \\ ${ }^{2}$ School of Architecture and Design, 3066 Tongzhi Street, Changchun, Jilin Province, P.R.China \\ ${ }^{3}$ School of Architecture and Design, 3066 Tongzhi Street, Changchun, Jilin Province, P.R.China \\ a76682911@qq.com, b742587202@qq.com, c1176811812@qq.com
}

\begin{abstract}
Keywords: Regional Culture; Changchun; Architectural Color; Influence
Abstract. There is a close relationship between architectural color and the formation of urban social historical context, the formation of urban features, urban residents' attachment, and so architectural color is an important part of urban features. The paper generalizes architectural color features during various stages of historical development in Changchun, analyzes the main factors influencing the formation of architectural color in Changchun from four aspects which are the natural environment, traditional regional culture, modern regional culture and building technology and material, proposes the planning proposals of architectural color in Changchun, and provides a reference for urban color planning of extending regional cultural feature.
\end{abstract}

\section{Introduction}

Color impacted on urban design really from the early 1960s, some developed countries in Europe and America began to take color as an important element in improving environment, showing urban context and extending urban features in the new urban planning design [1]. Because of regional differences, architectural color and regional culture are considered as expression form of national culture. Architectural color is also the main part of urban landscape, thus, architectural color accordingly become the leading role of urban color, which formed the urban unique color emotion and shows different urban art and features. Currently, the rush development of Chinese buildings enables urban design behind architectural design, and architectural color planning is not concerned. Even though there is more theoretical study, there is few real action. In addition to protection area of the city's historic district, color control has been put into effect, color choice of other buildings are lack of control rules in most cities.

\section{Significance of Architectural Color on Forming Urban Regional Features}

\section{Formation of Architectural Color and Urban Social History Context}

Architectural history is an important part of urban social culture history, and a pass to cultural information during a certain historical period, which contains the development context of urban political, religious, ethnic, class, geography, history, economy, technology, materials, and culture, and decides the architecture color choice intentions. Such as palaces' color since Tang Dynasty in China, yellow and red are based colors, which represent the imperial power, green, cyan, blue are colors for courtiers, black, gray, white are colors for people's houses, so color rule was to symbolize the political class hierarchy. Gold is the main color of Buddhist buildings, more warm colors are used in colorful and gorgeous Islamic buildings, architectural colors in medieval Europe are closely connected with religion; national characteristics were merged into buildings in Qing Dynasty, such as red walls, yellow tiles and scarlet pillars were used in palaces. Houses have their own characteristics according to geographical location, gray tiles, adobe and wood were used as masonry materials in the north, and more buildings' color is natural. White walls, gray tiles, brown pillars were used in the south, and more buildings' color is simple. 


\section{Formation of Architectural Color and Urban Features}

Urban features is the unique style and appearance which is different from other cities, was formed by integrating natural environment, history, environment, human environment, technical and economic environment after a long time of development accumulation. Urban features reflected in many aspects, but architectural color can express and reflect the spirit of the times, even more atmosphere of the urban life visually. A city with bright colors can bring a comfortable visual pleasure for people, and a city with simple and elegant colors can bring a quiet and peaceful feelings for people. so every city can form urban features by own unique tone and bring different feelings for people.

\section{Formation of Architectural Color and Urban Residents' Attachment}

Color will be a certain psychological implications in visual perception. Compared to color and building style art, color can be more easily identified and realized especially for the elderly and children who need higher recognition requirements, architecture color can play an important role in distinguishing identity in a residential community. Such as Marseilles, designed by Le Corbusier, a variety of bright colors were applied in the partition between the different units, high saturation of the red, yellow and blue colors bring personalized color for each individual dwelling units and formed a clear identification, which made the occupants easily find their own housing units outside the building by different colors[2]. This recognition gives people the most direct and most effective psychological implications, forms urban residents' attachment or a sense of belonging to familiar buildings, and then improves the place spirit of a city.

\section{Phase Features of Architectural Color in Changchun City}

In 1800, the Qing government established the Office of Changchun at Kuanchengzi, architectural color are based on red and gray, masonry materials are based on brick and wood. During Manchurian Railway subsidiary period in 1890, the main color of buildings is based on warm yellow and dark gray, partial decoration is based on white and red and so on. In 1932 the Japanese invaders made Changchun as the capital of puppet Manchukuo, renamed "New Beijing", as Manchukuo "political center" and developed the Changchun City Planning. With the establishment of Manchukuo eight portions, Puppet Palace, Manchukuo State Department, the command center of Japanese Kwantung Army in Northeast China and other public buildings, its facades as ceramic veneer are based on relatively quiet and warm colors such as coffee, brown, ocher and light yellow. Roofs were main dark. Residential buildings always used original color of brick and gray tiles. These typical building colors has become the mark of historic buildings in Changchun, has become a witness in Changchun history, which affected the building color in that location. By the 50s of last century, under the new Chinese planned economy system, Changchun has become a national heavy industrial base. Because of the Soviet Union's aid projects, its concept of design and urban planning affected the architectural style of the period. The development of industry pushed forward the urban construction, so many similar style factories and residential buildings were built in the short term. Industrial plants were mostly gray tone, and most dwellings used red brick walls. The brightness and saturation of Building color had been improved, and tended to brick red lines of moderate saturation. After the reform and opening, a lot of modern architecture came out, has changed the relative single situation of the original building color, formed the mixed pattern of building color with different ages. Facade materials are rich, but mostly based on paint, tile and glass, color choice were increased, due to the ease manufacture and low prices, these supplies are widely used in the late 20th century, especially in the construction of new urban area, gray, brick red, brown, khaki, white, blue and other colors are used in the buildings, lightness and saturation are overall increased, also exacerbated the contradictions and conflicts of urban color environment.

\section{Cause of Effecting Architectural Color Features in Changchun City}

Exploring the formation factors of architectural color features in Changchun, we need clear the constraints of impacting on urban architecture color. These constraints are living environment of 
architectural color. Driven by active choice and constraints, through the long-term selection of combined effects, the main tone urban building color was formed ultimately.

\section{Effect of Natural Environmental Conditions}

Changchun City is located in the north temperate latitudes in the Northern Hemisphere, is flat with convenient transportation. Soil and plants are natural background colors in Changchun spring and summer; red orange and brown are background colors in Changchun autumn; gray brown and silver are background colors in Changchun winter, so background colors in different seasons affect the architectural color choices. Changchun is located in cold areas, summer is short and warm, autumn is sunny and big temperature difference, and winter is long and cold, so climatic factors have a greater impact on the architectural color choices. Color has certain physical properties; different colors absorb the sun's different radiation and produce different physical properties. According to the characteristics, most building colors use darker warm gray tone, which is also helpful to seek balance with the psychological feelings visually in cold climates.

\section{Effect of the Traditional Region Culture}

Jilin Province is a major agricultural province, has a rich farming culture. As the capital city of Jilin Province, Changchun held the Agricultural Fair annually. Agricultural Fair as being in an "Agricultural Museum" displays farming life, agricultural customs, characteristics and culture, even the past that the ancestors did which people gradually forget, arouses people to value folk culture and take memories of past years. According to the doctrine of yin and yang, white is gold, wood is green, water is black, fire is red, soil is yellow. They correspond to the world in five directions, where yellow is in the center, which is the color of the land, in the land-based agricultural society, so roof of the palaces used yellow glazed tile, which mean sacred and majestic[3].

Shamanism is a primitive religion of Ancient North National universal faith. The Manchu believes and inherits shamanism in a long historical period. Jilin Province is one of the birthplaces of the world-recognized Shaman culture, Manchu culture is an important part of the regional culture in Changchun. Manchu built mud thatched cottage and brick stone houses with tile roof, its style is elegant, stately and rustic. The facade of brick wall lined up the joint with the rubbed brick, which looked dignified, flat, economical, durable, fireproofing and responded to white walls, so the overall style is fresh and elegant. Roofs were covered with gray tiles, and the ridge was used with bright gray, white and brown colors. Color of historical and national buildings impacted on the current architecture color tone directly in Changchun city.

\section{Effect of Building Technology and Materials}

Before The foundation of the people's republic of china restricted by building technology and materials, less material types are available. Architectural Color is relatively simple formed by yellow mud thatched cottage and brick tiles, so color performance is very limited, and most architectural colors are from material itself. Before the reform and opening, building technology and materials have certain development, more red brick, cement, paint, brick, stone and glass are used in the building. Even though lightness and color saturation has been increased, the whole tone is still relatively conservative. Building colors were based on red, green and gray as the main colors, the overall tone is more harmonious. After the reform and opening, building materials have a wide range of types, building color are showing a colorful situation. Application of modern technology and materials promote building color to have huge changes. In all the new development zone and Changchun city center, extensive glass, aluminum, steel, reinforced concrete and other modern materials were used, extensive paint, tile, marble, granite were used in the façade of buildings, which formed vivid building color of industrial characteristics. Building colors are rich, brightness and saturation have been significantly improved a lot, but coordination is not enough.

\section{Planning Proposals of Architectural Color in Changchun City}

Building urban regional culture style is the main goal of the future development of the city, which has become the consensus of the urban development, architectural color in Changchun has formed unique 
urban features during the history development process. In order to develop and continue this feature, the proposed construction in the future color planning should consider from the formation factors of impacting Changchun building color. First of all, it is to respect the geographical characteristics. The color of cold city is appropriate to use warm color, building materials are better to use local materials, which are both economical and match regional climate characteristics, so it is conducive to form urban regional features. Secondly, the region with the different cultural background uses different architectural color control system. To maintain the existing architectural color continuation in the blocks with historical features, such as Xinmin Street, blocks of Automobile factory, the color control guidelines with detailed planning need to be done. The most buildings in new district and the development zone are modern buildings, more types of materials are used, and main colors can be chose as medium color saturation to reflect the development vitality of new areas. Thirdly, buildings with different function use different color control system. Public buildings, especially high-rise buildings, according to the characteristics of building materials, can choose the warm gray or cold gray in medium or low saturation, residential buildings can choose warm colors of medium saturation which are easy to stimulate the inner sense of belonging and warmth.

\section{Conclusions}

Changchun is an orderly city with strict composition, although its history is relatively short, the atmosphere of regional culture style is rich. During the short development history of city, building color of each stage has a distinct feature style, has the footprint of the times, and loads the urban construction history of each era. We should realize architectural color as the important role in urban features objectively, and great value to form the region cultural features for Changchun city.

\section{Acknowledgements}

This work was financially supported by the project of Education Department of Jilin Province (2016 No. 321) "Research on design and planning about wineries in Jilin Province based on the concept of regional culture", the fund project of Philosophy and Social Science Planning of Jilin Province (2016B302)"Research on the Closure and Opening of Residential Community in Changchun City un der the Background of Opening the Enclosed Community", the project of Education Department of Jilin Province (2016 No. 319)"Research on the urban Feature of Changchun city based on new urbanization", the project of Education Department of Jilin Province (2015 No. 200)"Research on the urban Feature of Changchun city based on new urbanization", and the Youth Fund Project of Changchun Institute of Technology (320130023).

\section{References}

[1] Zhang Hailan, Shang Lei. Urban Color Design and Color Application [J]. Urban, 2004 (1): 49.

[2] Chen, Wei Chen. Expression and Planning of Urban Architecture Colors [J]. Urban Planning, 2001,25 (3): 61.

[3] Zhao Lin. Cultural Implications of Architectural Decoration - Shenyang Imperial Palace as an Example [J]. Urbanism and Architecture, 2013,(16)204. 